\title{
AN OVERVIEW OF NASA'S INTEGRATED DESIGN AND ENGINEERING ANALYSIS (IDEA) ENVIRONMENT
}

\author{
Jeffrey S. Robinson \\ NASA Langley Research Center \\ Hampton, Virginia \\ and \\ John G. Martin \\ NASA Langley Research Center \\ Hampton, Virginia
}

Joint Army-Navy-NASA-Air Force (JANNAF)

$6^{\text {th }}$ Modeling and Simulation $/ 4^{\text {th }}$ Liquid Propulsion $/ 3^{\text {rd }}$ Spacecraft

Propulsion Joint Subcommittee Meeting

Orlando, Florida

December 8-12, 2008 


\title{
AN OVERVIEW OF NASA'S INTEGRATED DESIGN AND ENGINEERING ANALYSIS (IDEA) ENVIRONMENT
}

\author{
Jeffrey S. Robinson \\ NASA Langley Research Center \\ Hampton, Virginia \\ and \\ John G. Martin \\ NASA Langley Research Center \\ Hampton, Virginia
}

\begin{abstract}
Historically, the design of subsonic and supersonic aircraft has been divided into separate technical disciplines (such as propulsion, aerodynamics and structures) each of which performs their design and analysis in relative isolation from others. This is possible in most cases either because the amount of interdisciplinary coupling is minimal or because the interactions can be treated as linear. The design of hypersonic airbreathing vehicles, like NASA's X-43, is quite the opposite. Such systems are dominated by strong non-linear interactions between disciplines. The design of these systems demands that a multi-disciplinary approach be taken. Furthermore, increased analytical fidelity at the conceptual design phase is highly desirable as many of the non-linearities are not captured by lower fidelity tools. Only when these systems are designed from a true multi-disciplinary perspective can the real performance benefits be achieved and complete vehicle systems be fielded.
\end{abstract}

Toward this end, the Vehicle Analysis Branch at NASA Langley Research Center has been developing the Integrated Design \& Engineering Analysis (IDEA) Environment. IDEA is a collaborative environment for parametrically modeling conceptual and preliminary launch vehicle configurations using the Adaptive Modeling Language (AML) as the underlying framework. The environment integrates geometry, configuration, propulsion, aerodynamics, aerothermodynamics, trajectory, closure and structural analysis into a generative, parametric, unified computational model where data is shared seamlessly between the different disciplines. Plans are also in place to incorporate life cycle analysis tools into the environment which will estimate vehicle operability, reliability and cost.

IDEA is currently being funded by NASA's Hypersonics Project, a part of the Fundamental Aeronautics Program within the Aeronautics Research Mission Directorate. The environment is currently focused around a two-stage-to-orbit configuration with a turbine based combined cycle (TBCC) first stage and reusable rocket second stage. This paper provides an overview of the development of the IDEA environment, a description of the current status and detail of future plans.

\section{INTRODUCTION}

In the world of conventional aircraft design, technical disciplines can operate in relative isolation from each other because cross-discipline interactions are often either minimal or at least can be treated as linear. On the contrary, the design of hypersonic airbreathing vehicles, like NASA's X-43 vehicle shown in Figure 1, is dominated by strong non-linear interactions. Take, for instance, the forebody and 
aftbody on the underside of vehicle. These surfaces provide the majority of the vehicle's total aerodynamic lift, but also act as the inlet and nozzle for the scramjet engine. As such, both the aerodynamic and propulsion disciplines are greatly affected by their design, which is often determined through a multi-disciplinary optimization performed at the vehicle level. Such trade-offs and multidisciplinary analyses are common for this class of vehicle and, in fact, are required in order to achieve their full performance potential ${ }^{1}$.

In the United States, the hypersonics community (government, industry and academia) strongly agree that the key to unlocking the potential in hypersonic aircraft lies in multidisciplinary analysis at the vehicle level and that

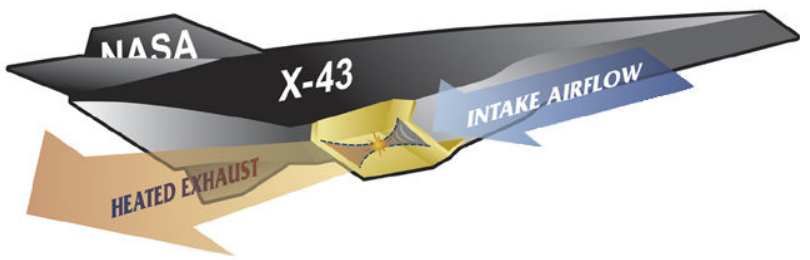
improvements in this capability are critical to future success. In 2005, at the request of the United States Congress, the National Institute of Aerospace (NIA) developed and released "Responding to the Call: Aviation Plan for American Leadership", a 1000+ page document which detailed the deterioration of America's dominance in aviation and aeronautics research. It provided, as a start towards recovery, a detailed plan in each of seven aeronautics sectors, among which was hypersonics. In the hypersonics plan, the first critical area identified was Multidisciplinary Design, Analysis and Optimization (MDAO), stating, "The highly integrated nature of hypersonic vehicles, combined with their high levels of technological and economic uncertainty, render conventional design practices inadequate for synthesizing systems to meet all performance, effectiveness, and economic requirements. Improved methods of system design that account for and even take advantage of the highly integrated nature of hypersonic vehicles are therefore crucial to their successful development." The plan went on to describe the components and attributes of an integrated design and optimization environment, saying that "Successful hypersonic vehicle design is not possible without such improved, integrated and automated methods." The need identified here by the NIA has also been detailed by the U.S. Air Force ${ }^{3}$, by Boeing ${ }^{4}$ and by NASA ${ }^{5}$.

\section{BACKGROUND}

Figure 2 shows the combination of analytical disciplines typically involved in the design, analysis \& optimization hypersonic airbreathing vehicles. Among these ten, "Life Cycle Analysis" encompasses an additional five disciplines that help to provide estimates of system cost, reliability and operability. Classic MDAO methods (response surface fitting techniques, multi-objective / multiattribute optimization, numerical smoothing, etc.) are captured under "Optimization \& Advanced MDAO Techniques". The remaining eight discipline areas are those that are traditionally included in determining the overall performance of the system.

Numerous attempts have been made

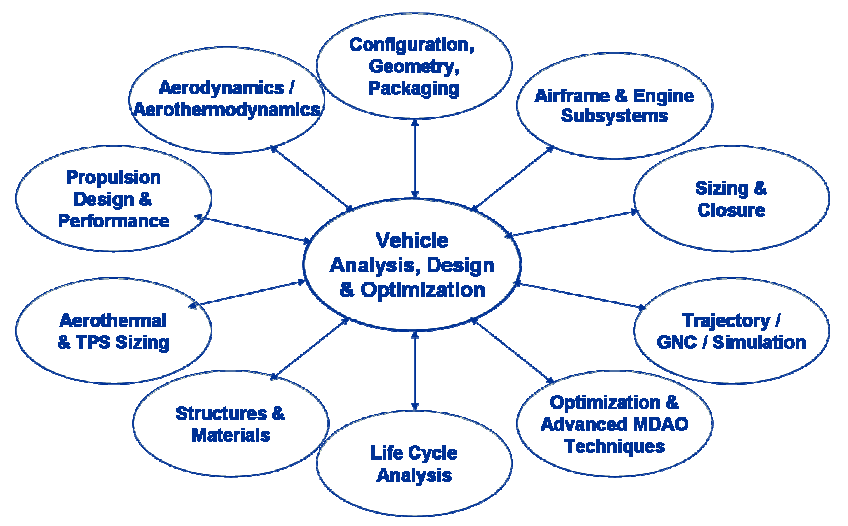

Figure 2. Graphic showing analytical disciplines involved in hypersonic systems analysis and design. in the past by NASA and others to integrate these disciplines into an environment. Different environment frameworks with varying levels of integration have been fielded with varying results. One of the more notable efforts in recent years was the Advanced Engineering Environment (AEE) ${ }^{6}$, funded by NASA"s Space Launch Initiative. AEE was built utilizing Phoenix Integration's ModelCenter ${ }^{\odot}$ framework. While AEE worked well for expendable and reusable rocket-based launch vehicles, it lacked the detailed geometry capability that is crucial to accurately model and analyze hypersonic airbreathing vehicles. The hypersonics group within Boeing recognized this need and endeavored to develop their own internal parametric geometry modeling capability that ultimately 
would become the heart of their environment, BIVIDS ${ }^{4}$. The Air Force also saw this need and found their answer $^{3}$ with the Adaptive Modeling Language $(A M L)^{7}$, a product of Technosoft, Inc. While it can communicate natively with other commercial CAD packages (Pro-E, Catia, etc.), AML and its environment, like the Boeing system, have at its core a parametric geometry modeling capability. This feature is critical, as it allows each discipline to natively share, understand and interpret the knowledge of the same geometry. Often, in the more typical design cycle where the disciplines are not well-integrated, it is common for each discipline to generate their own representation of the actual geometry, leading to innumerable inconsistencies and a configuration control nightmare. With AML controlling and distributing information about the geometry in the form required by each discipline, this issue is avoided. In addition to parametric geometry generation, other requirements for the environment include streamlined data transfer between analysis tools, automated coupling and execution of computational analyses, multidisciplinary design optimization methods, and probabilistic methods and processes that enable system level risk assessment / mitigation and robust vehicle configuration optimization. The environment must also support and integrate multiple levels of analytical fidelity.

The Air Force introduced AML to the hypersonics group in the Vehicle Analysis Branch (VAB) at NASA Langley in 1998. Since then, VAB has been partnering with Technosoft through a Small Business Innovative Research (SBIR) award to develop interfaces in the AML environment for some of VAB's legacy codes ${ }^{8}$. Initially focused on providing engineers with enhancements to their individual discipline tools, the focus has shifted over the last 2-3 years towards integrating these tools into a unified, multidisciplinary analysis and design capability. Known formerly as CoHAVE and AdVISE, the system is now referred to as the Integrated Design and Engineering Analysis (IDEA) Environment. The current effort is being supported by the MDAO discipline within the Fundamental Aeronautics Program's Hypersonics Project.

\section{DISCIPLINE FIDELITY LEVELS}

During NASA's Next Generation Launch Technology (NGLT) program, the Systems Analysis Project (SAP) conducted and coordinated multiple sets of system analyses across various missions and with varying levels of technology assumptions ${ }^{9}$. In order to get a better understanding of the differences between analyses and the level of uncertainty (generally) contained in each, the SAP endeavored to try and standardize definitions for the various levels of fidelity within each of the disciplines. The MDAO group within the Hypersonics Project has updated and adopted this matrix to help guide it with tool development and as a basis for comparing analytical results on system studies. The matrix includes five distinct levels of fidelity for the eight performance-related disciplines mentioned previously, plus two levels of fidelity for the five disciplines that make up life cycle analysis.

The updated matrix for the performance-related disciplines is shown in Table 1. As seen in the table, at the lowest level of fidelity (level 0 ), the disciplines typically employ historical or scaled empirical data in order to quantify vehicle performance. In general, uncertainty is expected to be the highest at this level, although computational speed and flexibility in the design space are the greatest. One can also relate the programmatic development cycle and the typical system breakdown structure (SBS) or system hierarchy (architecture $>$ major system $>$ element $>$ subsystem $>$ component $>$ subassembly $>$ part) ${ }^{10}$ to the various levels of fidelity. At the beginning of any program (pre-Phase A), trade studies and systems analyses are conducted at the highest SBS level, the architecture level. Here, the entire mission and its global requirements need to be considered in order to determine the performance required out of each of the major systems. This program phase and SBS level generally will incorporate analyses conducted at fidelity levels $0-1$. As a program progresses into Phase A, the level of detail in the design increases from the architecture and major system level down to the element level. This progression would correspond roughly with discipline analyses at fidelity level 2 and bring a design close to the System Requirement Review (SRR) project phase. As the level of fidelity and the amount of detail increase, the level of uncertainty in the design should correspondingly decrease, although computational speed continues to slow and design flexibility continues to become more limited. As detail increases to the subsystem and component levels, discipline fidelity increases to levels 3 and 4 and the program pushes towards Preliminary Design Review (PDR). At this point in the design, the majority of the design choices will have 


\begin{tabular}{|c|c|c|c|c|c|c|c|c|}
\hline $\begin{array}{c}\text { Fidelity } \\
\text { Level }\end{array}$ & $\begin{array}{c}\text { Configuration, } \\
\text { Geometry \& } \\
\text { Packaging }\end{array}$ & $\begin{array}{l}\text { Structures \& } \\
\text { Materials }\end{array}$ & Sizing \& Closure & $\begin{array}{c}\text { Trajectory, GNC \& } \\
\text { Simulation }\end{array}$ & $\begin{array}{l}\text { Propulsion Design \& } \\
\text { Performance }\end{array}$ & $\begin{array}{c}\text { Aerodynamics \& } \\
\text { Aerotherodynamics }\end{array}$ & $\begin{array}{c}\text { Aerothermal \& } \\
\text { TPS Sizing }\end{array}$ & $\begin{array}{c}\text { Airframe \& } \\
\text { Engine } \\
\text { Subsystems }\end{array}$ \\
\hline 0 & \begin{tabular}{|c|} 
Parametric, \\
empirical or \\
analytical geometry \\
model
\end{tabular} & \begin{tabular}{|c|} 
Parametric or \\
historical equations \\
adjusted to level 1 \\
or higher for similar \\
technology and \\
vehicle \\
configuration
\end{tabular} & $\begin{array}{c}\text { Weight \& volume closure w/ } \\
\text { consistent bookkeeping of all } \\
\text { propellants \& fluids based on } \\
\text { commensurate fidelity level } \\
\text { inputs from other disciplines; } \\
\text { As-Flown vehicle } \\
\text { photographic scale factor < } \\
+/-15 \% \text { from As-Drawn }\end{array}$ & $\begin{array}{c}\text { Rocket equation or } \\
\text { energy methods } \\
\text { (path following) } \\
\text { simulation }\end{array}$ & Scaled empirical & Scaled empirical & $\begin{array}{c}\text { Parametric or } \\
\text { Historical }\end{array}$ & $\begin{array}{l}\text { Parametric or } \\
\text { Historical }\end{array}$ \\
\hline 1 & \begin{tabular}{||c|} 
External \& major \\
internal components \\
modeled such as \\
propellant tanks. \\
Payload bay, \\
propulsion, etc... for \\
volume, area, and \\
key linear \\
dimensions
\end{tabular} & $\begin{array}{c}1 \mathrm{D} \text { bending loads } \\
\text { analysis based on } \\
\text { structural theory of } \\
\text { beams, shell, etc... } \\
\text { with non-optimums } \\
\text { based on level } 2 \text { or } \\
\text { higher results }\end{array}$ & $\begin{array}{c}\text { Weight \& volume closure w/ } \\
\text { consistent bookkeeping of all } \\
\text { propellants \& fluids based on } \\
\text { commensurate fidelity level } \\
\text { inputs from other disciplines; } \\
\text { As-Flown vehicle } \\
\text { photographic scale factor < } \\
+/-10 \% \text { from As-Drawn }\end{array}$ & $\begin{array}{c}\text { Optimized ascent, } \\
\text { flyback \& re-entry } 3 \\
\text { DOF point mass } \\
\text { simulation (un- } \\
\text { trimmed) }\end{array}$ & $\begin{array}{c}\text { 1D cycle analysis adjusted } \\
\text { to level } 2 \text { or higher results } \\
\text { (MIL standard or other } \\
\text { installation effects } \\
\text { included) }\end{array}$ & $\begin{array}{c}\text { Linear/impact methods with } \\
\text { all drag increments } \\
\text { (empirical) adjusted to level } \\
2 \text { or higher; vehicle satisfies } \\
\text { all takeoff/landing speeds, } \\
\text { glide path, and runway } \\
\text { length requirements }\end{array}$ & $\begin{array}{c}\text { Aerothermal } \\
\text { loads based on } \\
\text { 1D engineering } \\
\text { methods; } 1 \mathrm{D} \\
\text { thru the } \\
\text { thickness TPS } \\
\text { sizing }\end{array}$ & $\begin{array}{l}\text { Functional } \\
\text { definition \& } \\
\text { evaluation } \\
\text { and/or 1D or } \\
\text { generic } \\
\text { modeling of } \\
\text { subsystem }\end{array}$ \\
\hline 2 & \begin{tabular}{|c|} 
All components \\
modeled, packaged, \\
and analyzed for \\
geometric properties \\
including center of \\
gravity. Geometry re \\
drawn and packaged \\
to match closure \\
model
\end{tabular} & $\begin{array}{c}\text { Limited 3D FEA } \\
\text { (<20,000 nodes) for } \\
\text { all major load } \\
\text { cases, structure } \\
\text { sized to allowables, } \\
\text { non-optimums } \\
\text { determined } \\
\text { empirically or } \\
\text { analytically }\end{array}$ & $\begin{array}{c}\text { Weight \& volume closure w/ } \\
\text { consistent bookkeeping of all } \\
\text { propellants \& fluids based on } \\
\text { commensurate fidelity level } \\
\text { inputs from other disciplines; } \\
\text { As-Flown vehicle } \\
\text { photographic scale factor < } \\
\text { +/- } 5 \% \text { from As-Drawn }\end{array}$ & $\begin{array}{l}\text { Optimized ascent, } \\
\text { flyback \& re-entry } 3 \\
\text { DOF (pitch trim) } \\
\text { point mass } \\
\text { simulation; } \\
\text { longitudinal stability } \\
\text { \& control evaluation }\end{array}$ & \begin{tabular}{|c|} 
2D/3D finite difference \\
inviscid (Euler) flowfield \\
analysis w/ heat \\
conduction / transfer \& \\
integral boundary layer \\
analysis. Propulsive \\
moments, installation \\
effects \& thermal balance \\
computed.
\end{tabular} & $\begin{array}{c}\text { 3D CFD inviscid (Euler) w/ } \\
\text { integral boundary layer or } \\
\text { potential w/ semi-emperical } \\
\text { drag increments or thin } \\
\text { layer Navier Stokes w/ semi } \\
\text { emperical non-viscous drag } \\
\text { increments; vehicle satifies } \\
\text { all takeoff/landing speeds, } \\
\text { glide path, runway length, } \\
\text { and longitudinal stability } \\
\text { requirements }\end{array}$ & $\begin{array}{c}\text { 2D/3D } \\
\text { engineering } \\
\text { methods or CFD } \\
\text { based } \\
\text { aerothermal } \\
\text { loads w/ quasi- } \\
\text { 2D TPS sizing }\end{array}$ & $\begin{array}{l}\text { Quantitative } \\
\text { thermal \& fluid } \\
\text { analysis of } \\
\text { subsystem; } \\
\text { Component } \\
\text { weights } \\
\text { estimated w/ } \\
\text { empirical, } \\
\text { historical or } \\
\text { analytical } \\
\text { data/analysis }\end{array}$ \\
\hline 3 & \begin{tabular}{|c|} 
All components \\
modeled, packaged, \\
and analyzed for \\
geometric properties \\
including center of \\
gravity and inertia \\
characteristics. \\
Geometry re-drawn \\
and packaged to \\
match closure model
\end{tabular} & \begin{tabular}{|l} 
3D FEA ( $>20,000$ \\
nodes) for all major \\
load cases, \\
structure sized to \\
allowables, non- \\
optimums \\
determined \\
empirically or \\
analytically. \\
Dynamic \\
frequencies \\
estimated.
\end{tabular} & $\begin{array}{c}\text { Weight \& volume closure w/ } \\
\text { consistent bookkeeping of all } \\
\text { propellants \& fluids based on } \\
\text { commensurate fidelity level } \\
\text { inputs from other disciplines; } \\
\text { As-Flown vehicle } \\
\text { photographic scale factor < } \\
+/-3 \% \text { from As-Drawn }\end{array}$ & \begin{tabular}{|c|} 
Optimized ascent, \\
flyback \& re-entry 6 \\
DOFsimulation; \\
Iongitudinal, lateral \\
\& yaw stability \& \\
control evaluation; \\
perfect GN\&C
\end{tabular} & \begin{tabular}{|c|} 
2D/3D parabolized Navier- \\
Stokes finite difference / \\
volume flowfield analysis \\
w/ heat conduction / \\
transfer \& integral \\
boundary layer analysis. \\
Propulsive moments, \\
installation effects \& \\
thermal balance \\
computed. Full \\
mechanical design.
\end{tabular} & $\begin{array}{c}\text { 3D CFD parabolized Navier } \\
\text { Stokes (PNS) finite } \\
\text { difference / volume flowfield } \\
\text { analsis w/ heat conduction / } \\
\text { transfer \& integral boundary } \\
\text { layer analysis; vehicle } \\
\text { satifies all takeoff/landing } \\
\text { speeds, glide path, runway } \\
\text { length, and longitudinal, } \\
\text { lateral \& yaw stability } \\
\text { requirements }\end{array}$ & $\begin{array}{c}\text { 2D/3D CFD } \\
\text { based } \\
\text { aerothermal } \\
\text { loads w/ quasi- } \\
\text { 2D TPS sizing }\end{array}$ & $\begin{array}{l}\text { Quantitative } \\
\text { thermal \& fluid } \\
\text { analysis of } \\
\text { subsystem; } \\
\text { Component } \\
\text { weights } \\
\text { estimated w/ } \\
\text { empirical, } \\
\text { historical or } \\
\text { analytical } \\
\text { data/analysis }\end{array}$ \\
\hline 4 & \begin{tabular}{|c|} 
All components \\
modeled, packaged, \\
and analyzed for \\
geometric properties \\
including center of \\
gravity and inertia \\
characteristics. \\
Geometry re-drawn \\
and packaged to \\
match closure model
\end{tabular} & \begin{tabular}{|c|} 
3D FEA (>100,000 \\
nodes) for all major \\
load cases, \\
structure sized to \\
allowables, non- \\
optimums \\
determined \\
empirically or \\
analytically. \\
Dynamic \\
frequencies \\
estimated.
\end{tabular} & $\begin{array}{c}\text { Weight \& volume closure w/ } \\
\text { consistent bookkeeping of all } \\
\text { propellants \& fluids based on } \\
\text { commensurate fidelity level } \\
\text { inputs from other disciplines; } \\
\text { As-Flown vehicle } \\
\text { photographic scale factor < } \\
\text { +/- } 1 \% \text { from As-Drawn }\end{array}$ & $\begin{array}{c}\text { Optimized ascent, } \\
\text { flyback \& re-entry 6- } \\
\text { DOFsimulation; } \\
\text { longitudinal, lateral } \\
\text { \& yaw stability \& } \\
\text { control evaluation; } \\
\text { real GN\&C w/ gain } \\
\text { scheduling (or } \\
\text { similar) lags, noise, } \\
\text { etc }\end{array}$ & $\begin{array}{l}\text { 3D full or thin-layer Navier- } \\
\text { Stokes (FNS or TLNS) } \\
\text { flowfield analysis including } \\
\text { pressure feedback, shear } \\
\text { stress \& heat transfer } \\
\text { effects computed directly. } \\
\text { Propulsive moments, } \\
\text { installation effects \& } \\
\text { thermal balance } \\
\text { computed. Full } \\
\text { mechanical design. }\end{array}$ & \begin{tabular}{|} 
3D CFD full or thin layer \\
Navier-Stokes (FNS or \\
TLNS) flowfield analsis \\
including pressure \\
feedback, shear stress \& \\
heat transfer efects \\
computed directly; vehicle \\
satifies all takeoff/landing \\
speeds, glide path, runway \\
length, and longitudinal, \\
lateral \& yaw stability \\
requirements
\end{tabular} & $\begin{array}{l}\text { 3D CFD based } \\
\text { aerothermal } \\
\text { loads } w / 3 D \\
\text { TPS sizing }\end{array}$ & $\begin{array}{l}\text { Quantitative } \\
\text { thermal \& fluid } \\
\text { analysis of } \\
\text { subsystem; } \\
\text { Component } \\
\text { weights } \\
\text { estimated w/ } \\
\text { empirical, } \\
\text { historical or } \\
\text { analytical } \\
\text { data/analysis }\end{array}$ \\
\hline
\end{tabular}

Table 1. Analysis requirements and methodology differences for performance-related disciplines at various levels of analytical fidelity.

been made and standard systems engineering takes over to complete detailed subassembly and part specifications.

Within the MDAO discipline of the Hypersonics Project, architecture level trade studies and systems analyses are performed using the EXAMINE tool ${ }^{11}$. EXAMINE, developed over the last 4 years at NASA Langley, is a collection of Microsoft Excel ${ }^{\odot}$ workbooks that contain empirical data and mass estimating relationships (MERs), i.e. data at fidelity level 0 , for numerous vehicle classes and related subsystems. EXAMINE offers the ability to rapidly perform trade studies at the architecture level to help guide major system and element requirements. The IDEA environment is currently being targeted towards fidelity level 2. Fidelity level 1 will be addressed through the combination of level 1 analytical tools, where they exist (such as APAS and SHABP for high speed aero), and through abstractions of data generated at level 2 (like a response surface of CFD for lowspeed aero or 1-D structural beam models calibrated to level 2 finite element models).

Care is also being taken to make sure that IDEA can readily support analyses at higher fidelity levels. One such effort is aimed at automated generation of structured CFD grids to be used with the 
Vulcan CFD code ${ }^{12}$. Vulcan is a structured code that solves the full Navier-Stokes equations for turbulent, non-equilibrium, chemically reacting flows ${ }^{13}$. During the $X-43$ program, Vulcan was used to compute full vehicle powered solutions that were found to compare extremely well with flight data ${ }^{14}$. Vulcan has also shown excellent agreement with powered and unpowered tests in Langley's 8-ft. High Temperature Tunnel, as well as other scramjet and highspeed test facilities. In 2003, Vulcan was used to compare to a simulated powered test of a rocket-based combined cycle (RBCC) vehicle in Langley's 16-ft transonic facility, again with excellent agreement ${ }^{15}$. As such, Vulcan has become the benchmark CFD tool at Langley for hypersonic vehicles, and being able to support it directly with automated grid generation from IDEA is essential.

Table 2 shows the definition of the current two levels of fidelity for the five life cycle-related disciplines. With more development, the desire is to expand this matrix to include as many levels as there are in the performance-related discipline matrix. After a survey of existing methods, however, only two levels of fidelity could be distinguished and in many cases, the tools that fit this categorization either don't exist or are woefully inadequate to try and represent hypersonic airbreathing systems. As such, the Hypersonics Project is endeavoring, largely through the use of NASA Research Announcements (NRAs), to begin to fill some of these gaps. One such NRA is with Spaceworks, Inc., who are developing a discrete event simulation of operations for hypersonic vehicles ${ }^{16}$. Built using Arena ${ }^{\odot}$, the "Descartes" tool will provide estimates of the operational characteristics of the vehicle such as turn around time and operations cost. The Hypersonics Project is also planning to issue a similar award through the NRA process for development of an improved safety and reliability tool for hypersonic systems.

\begin{tabular}{|c|c|c|c|c|c|}
\hline $\begin{array}{l}\text { Fidelity } \\
\text { Level }\end{array}$ & Safety \& Reliablity & $\begin{array}{l}\text { Maintainability \& } \\
\text { Supportability }\end{array}$ & Operations & Cost & Economics \\
\hline $0-2$ & \begin{tabular}{||c} 
Propulsion, TPS and \\
other subsystems \\
estimated from aircraft \\
\& space vehicle \\
historical data \& \\
adjusted for advanced \\
technology increments
\end{tabular} & $\begin{array}{l}\text { Propulsion, TPS and } \\
\text { other subsystems } \\
\text { estimated from aircraft } \\
\& \text { space vehicle } \\
\text { historical data \& } \\
\text { adjusted for advanced } \\
\text { technology increments }\end{array}$ & $\begin{array}{c}\text { Propulsion, TPS and } \\
\text { other subsystems } \\
\text { estimated from aircraft \& } \\
\text { space vehicle historical } \\
\text { data \& adjusted for } \\
\text { advanced technology } \\
\text { increments }\end{array}$ & $\begin{array}{l}\text { Weight based CER's derived } \\
\text { from aircraft or space vehicle } \\
\text { historical data with } \\
\text { adjustments for technology } \\
\text { complexity; Economic theory } \\
\& \text { methods using to } \\
\text { determine business case }\end{array}$ & $\begin{array}{c}\text { Weight based CER's } \\
\text { derived from aircraft or } \\
\text { space vehicle historical data } \\
\text { with adjustments for } \\
\text { technology complexity; } \\
\text { Economic theory \& methods } \\
\text { using to determine business } \\
\text { case }\end{array}$ \\
\hline $3-4$ & $\begin{array}{c}\text { Component level } \\
\text { bottoms-up reliability \& } \\
\text { safety assessment }\end{array}$ & $\begin{array}{l}\text { Component level } \\
\text { bottoms-up O\&M } \\
\text { assessment }\end{array}$ & $\begin{array}{c}\text { Component level bottoms } \\
\text { up reliability } \& \text { safety } \\
\text { assessment }\end{array}$ & $\begin{array}{c}\text { Component level bottoms-up } \\
\text { O\&M assessment }\end{array}$ & $\begin{array}{l}\text { Component level bottoms- } \\
\text { up O\&M assessment }\end{array}$ \\
\hline
\end{tabular}

Table 2. Analysis requirements and methodology differences for life cycle-related disciplines at various levels of analytical fidelity.

\section{IDEA CONTENTS AND CAPABILITIES}

While multiple vehicle classes will ultimately be defined within IDEA (e.g. waveriders, "beta" boosters, vehicles with 3-D inlets, etc.), the current environment is built around a fully reusable two-stage-to-orbit (TSTO) system that employs a turbine-based combined cycle (TBCC) lifting-body first stage and a rocket-based winged-body second stage, similar to that shown in Figure 3. As mentioned, development of the IDEA environment is currently being focused around the discipline tools that meet fidelity level 2 requirements. In the Configuration, Packaging and Geometry discipline, AML will provide the fully parametric geometry modeling capability. A packaging system has also been created in IDEA that allows the user to select from a wide range of predefined packaging geometries, to import one from

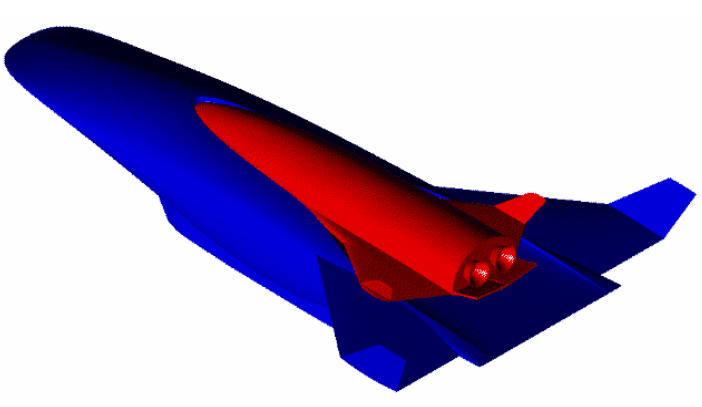

Figure 3. Two-stage-to-orbit launch vehicle concept with turbine-based combined cycle first stage and reusable rocket powered second stage. 
another CAD system, or to generate one from scratch. The packaging system has knowledge of the vehicle outer mold line (OML) geometry and thus can automatically shape packaging elements to be conformal with the vehicle OML. This feature is quite useful when modeling conformal fuel tanks, payload bays with doors that conform to the OML, or laying out structural elements (bulkheads, longitudinal beams, etc) that conform to the vehicle OML. The packaging system is also generic in that the OML being packaged can come either internally from AML or imported from another CAD system, such as through IGES translation. This still allows for designs created outside of the IDEA environment to be analyzed with IDEA, though the geometry would not be parametric, making modification very difficult. A sample packaging of the

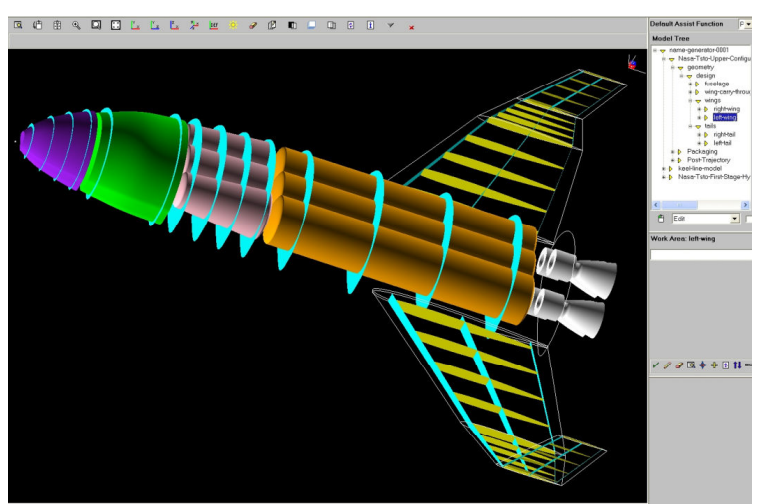

Figure 4. Sample internal packaging and structural arrangement for the second stage. second stage is shown in Figure 4. With each packaging element, mass properties can be assigned (either through a lumped amount or through an alternate estimating method, i.e. an MER) or calculated based on the packaging element geometry and a table of material properties. The mass properties management system within IDEA can then easily generate integrated mass properties for the entire vehicle. Several enhanced features are also under development, including time dependent and trajectory dependent mass properties. Here, the goal is to feed back time histories from the trajectory simulation of vehicle attitude, acceleration and propellant usage to the mass properties module in order to generate trajectory specific propellant loading states and corresponding mass properties.

In the Structures and Materials discipline, as mentioned previously, structural elements are created as part of the packaging system. This allows them to be conformal with the vehicle OML. Knowledge of the other packaging elements also allows automated cutouts in the shape of each element to be made in the structure to accommodate them. Once the structure has been laid out, the individual elements are sewn together and passed to Patran ${ }^{\odot}$ to be meshed. A sample mesh of the second stage is shown in Figure 5. Once the mesh is ready, it is combined with load case information generated from the trajectory and passed to Nastran ${ }^{\odot}$ to generate structural deflections. This information will then be passed to Hypersizer ${ }^{\odot}$, a commercial structural sizing program from Collier Research Corporation, in order to generate masses for each of the structural components. Several iterations of this loop will be required to generate a final set of structural element masses, which guarantees that all bending and deformation constraints have been satisfied. A more detailed description of the structures module has been documented separately ${ }^{17}$. Once this sizing system is in place, it can easily be extended to

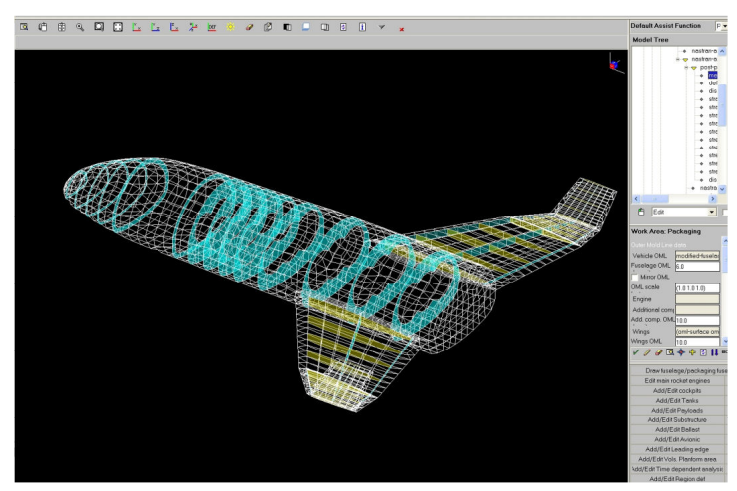

Figure 5. Snapshot of a sample structural mesh generated for the second stage. allow structural dynamics analyses as well as analyses of hot structures.

For Trajectory, GNC and Simulation, the IDEA environment will employ the POST2 trajectory $\operatorname{code}^{18}$. POST2 is an industry standard point mass trajectory tool for simulating motion of powered or unpowered vehicles near an arbitrary, rotating, oblate attracting body. POST2 can be run in various modes encompassing levels of fidelity one through four, depending on options selected and data inputs. For IDEA, a generalized user interface has been developed that offers full access to all inputs available in POST2. At many points in the input setup, depending on the selection of various methods and operational flags, many of the input variables available in POST2 become invalid. Intelligence has been added to the interface to only display those variables and options that are valid. All POST2 event types (primary, secondary, roving, repeating) are available through the interface, allowing a completely generic capability. 
Options to perform automated trade studies and Monte Carlo analysis have also been incorporated. Within IDEA, the POST2 interface has been integrated with other discipline tools to allow automated population of vehicle data into the input deck. Output from POST2 is also used by several disciplines. Trajectory information is used to generate loads analysis cases for structural sizing and will be used for sizing the thermal protection system (TPS) and various airframe and engine subsystems. Propellant usage is used by the Sizing and Closure discipline to size the vehicle to a given mission, as described below.

The Sizing and Closure methodology in IDEA utilizes an "as drawn" and a scaled version of the vehicle geometry. Initially, the vehicle geometry is defined at the "as drawn" level. For instance, for the second stage of the TSTO model, the vehicle is defined by roughly 30 or so parameters, mostly physical dimensions of each of the main parts of the vehicle. Each of these parameters has a property that determines whether that parameter is allowed to vary or not, as the vehicle is scaled, as well as setting a minimum or maximum allowable value for that parameter. The same is true for the payload bay and cockpit if those items are selected to be included in the vehicle packaging. Once those elements are packaged and volume is allocated for propulsion systems, the remaining vehicle length is left to be filled with propellant tanks. Tanks are set up such that their heights and widths are defined as percentages of the vehicle OML, allowing the cross-section distribution to remain relatively constant as the vehicle is scaled. Once the tanks are packaged, the propellant fraction available (PFA) is computed. Vehicle data (aerodynamic \& propulsion databases, mass properties, etc.) are sent to the POST2 trajectory module which flies the vehicle, optimizes on the given mission, and returns a propellant fraction required (PFR). The "scaled" version of the geometry is then scaled up or down appropriately until PFA equals PFR. Scaling is photographic unless a scaling constraint is reached. For example, if a payload of fixed length, width and height is packaged, at some point when photoscaling down, continued scaling of the OML would result in the payload no longer fitting, likely either in height or width. Here, scaling in that direction (height, width or both) would cease, and scaling would continue in directions not constrained. When scaling reaches the point where PFA equals PRF, new vehicle data is generated for the scaled version of the vehicle and passed to trajectory again for analysis. This cycle continues until convergence is achieved. The same closure process is currently being implemented for the first stage.

Three main elements make up the tool suite for the Propulsion discipline. For liquid and solid rockets, IDEA utilizes a rocket performance and sizing module built in AML by the U.S. Air Force and Technosoft that the Air Force uses in its Reusable Military Launch System (RMLS) and Integrated Propulsion Analysis Tool (IPAT) environments ${ }^{3}$. This module provides the user with the ability to select an existing engine from a database of over 40 predefined engines or to create a new engine by specifying some general information about the engine and picking propellants from a list of nearly 40 fuels and seven oxidizers. The module comes with mass estimating relationships based on physical dimensions and operating characteristics of the engine. For scramjet engines, IDEA utilizes the SRGULL code $^{19}$, a tip-to-tail hypersonic cycle analysis tool developed and used extensively at NASA Langley. SRGULL uses a

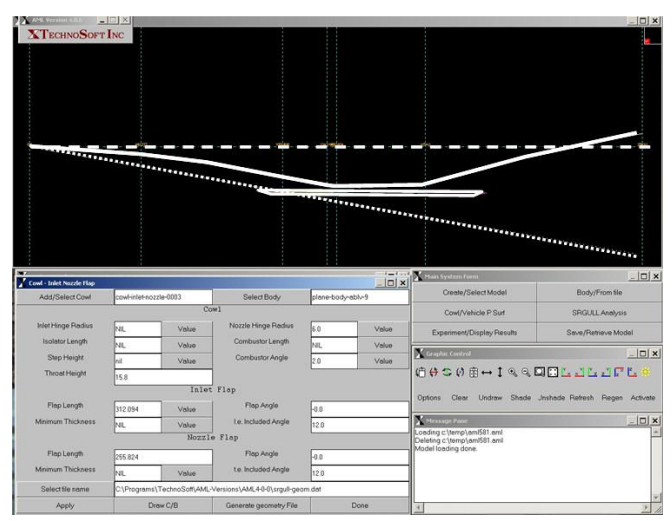

Figure 6. Snapshot of SRGULL / keel line design interface in IDEA. two-dimensional Euler method for the forebody / inlet and nozzle and a one-dimensional incremental combustor with an integral boundary layer method for all components. A snapshot of the interface for the SRGULL code that has been developed in IDEA is shown in Figure 6. For the TSTO vehicle class that IDEA is currently centered around, the keel line design from which the first stage is lofted comes from SRGULL. For turbine analysis, plans are in place to integrate IDEA with the Numerical Propulsion System Simulation (NPSS) tool from NASA Glenn ${ }^{20}$. NPSS has become an industry standard cycle analysis tool in the turbomachinery world and is currently in use by all of the major aircraft engine manufacturers.

Tools employed within the Aerodynamics and Aerothermodynamics discipline vary based on the flight condition being analyzed. For highspeed calculations (Mach $>3$ ), the IDEA environment will rely 
mostly on $\mathrm{APAS}^{21}$ and $\mathrm{SHABP}{ }^{22}$, both of which have been integrated into IDEA, to generate aerodynamic and heat transfer information. A snapshot of an SHABP run on the first stage is shown in Figure 7. Solutions from these codes will continuously be checked and updated with higher fidelity information from a variety of CFD codes. For lowspeed aerodynamics (Mach < 3), several options are currently under evaluation to support the environment. The most likely candidate at this point is to use CART3D ${ }^{23}$, an Euler code from NASA Ames, with an integral boundary layer method. A design of experiments will also likely be used in conjunction with CART3D to reduce the required number of cases. Other options under examination include a parabolized Navier-Stokes solver and potential flow panel methods. Each of these options has benefits and

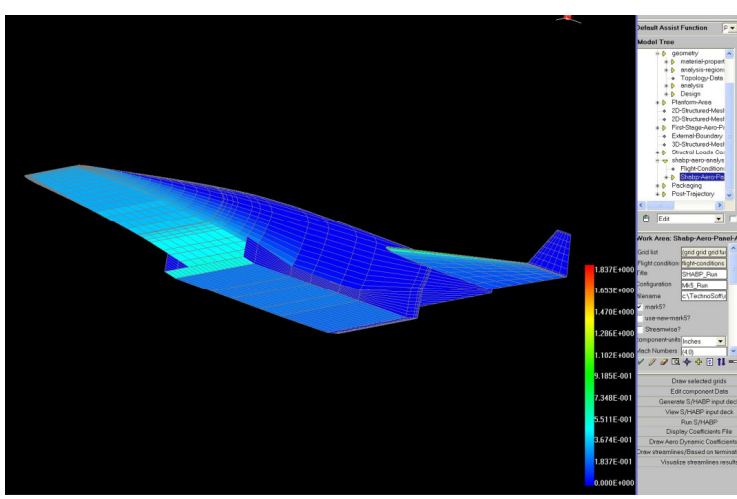

Figure 7. Snapshot of pressure coefficient distribution for a sample flight condition generated by SHABP on the first stage. drawbacks that will be weighed as the proper mix of speed and accuracy are balanced.

In the Aerothermal and TPS Sizing discipline, plans are in place to incorporate the TPSit code ${ }^{24}$, a TPS sizing tool under development by the Vehicle Technology Integration (VTI) discipline of the Hypersonics Project. TPSit is a finite element based heat transfer code used for approximating transient temperature distributions in one-dimensional (plug) models of thermal protection systems (TPS). Basic element groups, which model heat transfer based on conductivity and capacitance of solids, radiation, convection within gases, and lumped mass thermal capacitance, are utilized as building blocks for model construction and assembly of any TPS concept. Pressure and aerothermal heating, radiation to space, and convection to an ambient temperature are used to define boundary conditions. VTI is also developing (both in house and through NRA awards) structurally-integrated TPS concepts and related design tools that will be evaluated for use in IDEA. Also, as mentioned previously, future plans for the structural sizing module currently under development in IDEA include an extension towards analysis of hot structures.

In the Airframe and Engine Subsystems area, the plan is to implement existing MERs for all major engine and airframe subsystems. Currently, EXAMINE has several sets of MERs that include varying technology assumptions. The near term goal will be to implement such a suite of MERs. In the long term, as dictated by the fidelity matrix in Table 1 for level 2, more rigorous, physics-based models of subsystems will be built that consider loading and environment information from the trajectory simulation, plus thermal and power balance analyses, all of which influence the mass and volume of the individual subsystem. Ideally, even more meta-data will be tied or estimated for each system based on its characteristics, such as technology level, failure rate, failure mode, maintenance requirements, etc. that can be used to feed life cycle analyses estimates for the entire vehicle.

For Life Cycle Analysis, as mentioned previously, several tools are under development or planned through NASA's NRA process. Spaceworks Engineering is currently developing a discrete event simulation of vehicle operations which will be able to estimate vehicle characteristics such as turn-around time, maintenance requirements and operations cost. For development costs, IDEA will utilize the NASA / Air Force Cost Model (NAFCOM) with some model updates to better account for some of the airbreathing specific elements of the vehicles of interest. Elsewhere, the Hypersonics Project plans to issue a topic area in an upcoming NRA call for improved safety and reliability models for hypersonic vehicles. This call is expected to contain elements both for models at the subsystem level, which can be integrated into subsystem models under development in IDEA, as well as vehicle level methods for reliability estimation.

\section{SCHEDULE AND ROADMAP}

The IDEA environment is being rolled out over several major milestones. Each generation of IDEA will build upon the previous release. An overall schedule for the rollout is shown in Figure 8. Generation 0, which was just completed, provided the basic building blocks for performing vehicle 
closure. The POST2 trajectory interface was combined with the sizing and closure algorithms mentioned previously that, when combined with the automated parametric packaging capability, could automatically resize and close the second stage to a given mission. Significant effort was spent making the closure process robust, ensuring that from a wide range of initial inputs (vehicle dimensions, propellant choices, mission parameters, etc) that the closure system was stable and would converge to a solution. The final test for Generation 0 was an automated run of 117 design of experiments (DOE) cases that varied propellant choice, staging conditions, payload mass, vehicle fineness and engine design parameters for the second stage. The entire matrix was run, each starting from the same as drawn vehicle definition, without any failures, resulting in closed vehicles with gross weights varying from 90,000 to $800,000 \mathrm{lbs}$ and lengths from 55 to 127 feet. This methodology is now being implemented on the first stage to achieve complete system closure.

Generation 1 will incorporate the completed structural sizing module currently under development, along with TPS sizing, turbine propulsion modeling, lowspeed aerodynamics and enhanced subsystem modeling. As shown, several of the modules under development are dependent on inputs and models from other disciplines within the Hypersonics Project. The guidance, navigation and control (GNC) discipline will be supplying methods for stability and control evaluation, along with advanced, physicsbased actuator sizing routines. The materials and structures (M\&S) discipline is assisting with the TPS sizing routines, and the propulsion discipline (Prop) is integrally involved in the automated CFD meshing and lowspeed propulsion integration. As seen, the current timeline shows Generation 1 delivery near the end of FY10.

While Generation 1 will complete the integration of the performance-based disciplines into IDEA, Generations 2 and 3 will develop and integrate the life cycle tools into the environment. As shown and previously discussed, several of these models are currently under development through the NRA process, and several more are planned. Additionally, higher fidelity analysis capabilities, such as analysis of hot structures or structural dynamics models, will be included. Generation 2 will also begin to expand on the vehicle classes that are included in IDEA.

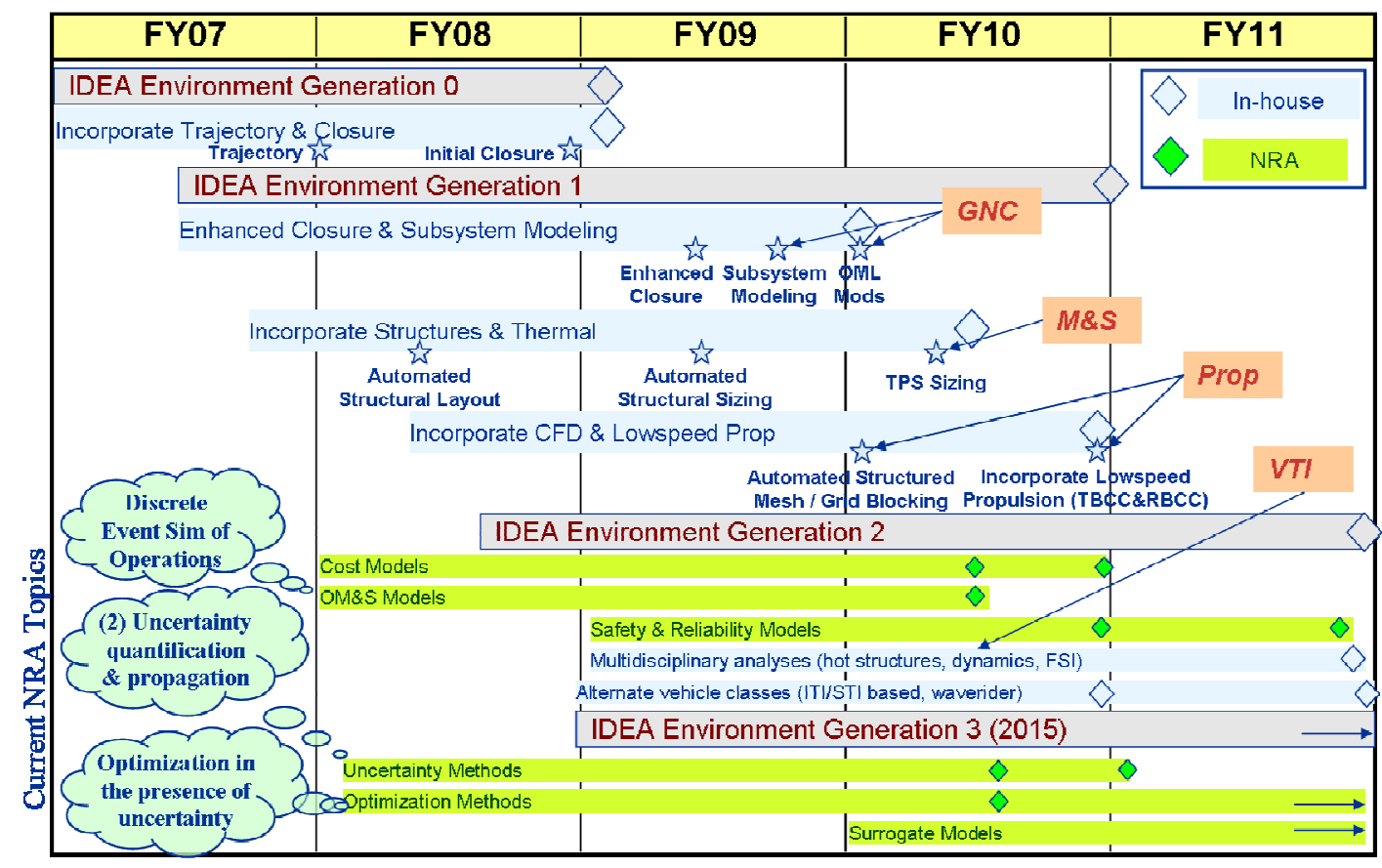

Figure 8. Schedule and major milestones for IDEA development and rollout. 


\section{SUMMARY AND CONCLUSIONS}

Hypersonic airbreathing systems, with their high level of integration and non-linear crossdiscipline coupling, demand that a multi-disciplinary approach be taken for their design, analysis and optimization. To solve this problem, NASA's Hypersonics Project is currently developing the Integrated Design and Engineering Analysis (IDEA) environment. IDEA is a collaborative environment for parametrically modeling conceptual and preliminary launch vehicle configurations using the Adaptive Modeling Language (AML) as the underlying framework. The environment integrates geometry, packaging, subsystems, propulsion, aerodynamics, aerothermodynamics, trajectory, closure, and structural analysis into a generative, parametric, unified computational model where data is shared seamlessly between the different disciplines. A matrix of various fidelity levels for each of these disciplines has been introduced. IDEA environment development is currently being focused on mid-level fidelity analyses, i.e. those that should be sufficient to bring a concept to a System Requirements Review phase of a project. Substantial progress has been made in the development. The first version of the environment, Generation 0 , has already been completed and work is well underway on future releases.

\section{REFERENCES}

\footnotetext{
${ }^{1}$ Moses,P.L., Bouchard,K.A., Vause,R.F., Pinckney,S.Z., Ferlemann,S.M., Leonard,C.P., Taylor,L.W.III, Robinson,J.S., Martin,J.G., Petley,D.H. and Hunt,J.L.; Design and Development of an Airbreathing Launch Vehicle with Turbine-Based Lowspeed and Dual Mode Ramjet / Scramjet Highspeed Propulsion; presented at the 36th JANNAF CS/APS/PSHS Joint Meeting, Cocoa Beach, FL; October 1999.

${ }^{2}$ Responding to the Call: Aviation Plan for American Leadership; published by the National Institute of Aerospace, Hampton, VA; 2005. (http://www.nianet.org/pubs/AviationPlan.php)

${ }^{3}$ Zweber,J.V., Kabis,H., Follett,W.W., and Ramabadran,N.; Towards an Integrated Modeling

Environment for Hypersonic Vehicle Design and Synthesis; AIAA-2002-5172; September 2002.

${ }^{4}$ Bowcutt,K.G., Kuruvila,G., Grandine,T.A., Hogan,T.A., and Cramer,E.J.; Advancements in Multidisciplinary Design Optimization Applied to Hypersonic Vehicles to Achieve Closure; AIAA2008-2591; April 2008.

${ }^{5}$ Robinson,J.S., Martin,J.G., Bowles,J.V., Mehta,U.B., and Snyder,C.A.; An Overview of the Role of Systems Analysis in NASA's Hypersonics Project; AIAA-2006-8013; November 2006.

${ }^{6}$ Monell,D., Mathias,D., Reuther,J., and Garn,M.; Multi-Disciplinary Analysis for Future Launch Systems Using NASA's Advanced Engineering Environment (AEE); AIAA-2003-3428; June 2003. ${ }_{7}^{7}$ The Adaptive Modeling Language, TechnoSoft, Inc., Cincinnati, OH; (http://www.technosoft.com/)

${ }^{8}$ Ferlemann,S.M., Robinson,J.S., Leonard,C.P., Taylor,L.W.III, Martin,J.G. and Kamhawi,H.; Developing Conceptual Hypersonic Airbreathing Engines Using Design of Experiments Methods; AIAA-20002694; June 2000.

${ }_{9}^{9}$ Bilardo,V.J., Robinson,J.S., Komar,D.R., Taylor,W., Lovell,N.T. and Maggio,G.; NGLT Systems Analysis Tiger Team Results: Implications for Space Launch Architectures and Technologies AIAA 2003-5263; July 2003.

${ }^{10}$ Hammond,W.E.; Design Methodologies for Space Transportation Systems; AIAA Educational Series, 2001.

${ }^{11}$ Komar,D.R., Hoffman,J., Olds,A., and Seal,M.; Framework for the Parametric System Modeling of Space Exploration Architectures; AIAA 2008-7845; September 2008.

${ }^{12}$ Ferlemann,P. and Kamhawi,H.; Automated Structured CFD Mesh Generation in NASA's IDEA

Environment; presented at the JANNAF Modeling \& Simulation Meeting, December 2008.

${ }^{13}$ White, J.A., and Morrison, J.H.; A Psuedo-Temporal Multi-Grid Relaxation Scheme for Solving the Parabolized Navier-Stokes Equations; AIAA 99-3360; July 1999.

${ }^{14}$ Ferlemann,P.; Hyper-X Mach 10 Scramjet Preflight Predictions and Flight Data; AIAA-2005-3352; May 2005.

${ }^{15}$ Meyer,B.; A Comparison of Computational Results with Transonic Test Data from a Hypersonic Airbreathing Model with Exhaust Simulation; AIAA-2003-4411; July 2003.
} 
${ }^{16}$ DePasquale,D., Kelly,M., Charania,A.C., and Olds,J. ;Activity-Based Simulation of Future Launch Vehicle Ground Operations; AIAA-2008-7660; September 2008.

${ }^{17}$ Eldred,L. and Kamhawi,H.; Automated Structural Analysis in NASA's IDEA Environment; presented at the JANNAF Modeling \& Simulation Meeting, December 2008.

${ }^{18}$ Striepe, S.A., Powell, R.W., Desai, P.N., Queen, E.M., Brauer, G.L., Cornick, D.E., Olson, D.W., Petersen, F.M., Stevenson, R., Engel, M.C., Marsh, S.M., and Gromoko, A.M., Program to Optimize Simulated Trajectories (POST II), Vol. II Utilization Manual Version 1.1.6.G, January 2004, NASA Langley Research Center, Hampton, VA.

${ }_{19}$ Pinckney, S.Z. and Walton, J.T., "Program SRGULL: An Advanced Engineering Model for the Prediction of Airframe-Integrated Subsonic/Supersonic Hydrogen Combustion Ramjet Cycle Performance", NASP TM-1120, January 1991.

${ }^{20}$ Evans, A.L., et al.: Numerical Propulsion System Simulation's National Cycle Program. AIAA-983113, 1998.

${ }^{21}$ Sova, G., Divan, P., Aerodynamic Preliminary System II, North American Aircraft Operations, Rockwell International, Los Angeles, CA.

${ }^{22}$ Gentry, A. E., Smyth, D. N., Oliver, W. R., The Mark IV Supersonic-Hypersonic Arbitrary-Body Program, McDonnell-Douglas Corporation, Technical Report AFFDL-TR-73-159, November 1973.

${ }^{23}$ Aftosmis, M.J., Berger, M.J., and Adomavicius, G. D. A parallel multilevel method for adaptively refined Cartesian grids with embedded boundaries, in Proc. 38th AIAA Aerospace Sciences Meeting \& Exhibit, Paper 2000-0808, Reno, NV, Jan. 2000.

${ }^{24}$ Myers,D.E., Martin,C.J. and Blosser,M.L.; Parametric Weight Comparison of Advanced Metallic, Ceramic Tile, and Ceramic Blanket Thermal Protection Systems; NASA/TM-2000-210289, June 2000. 